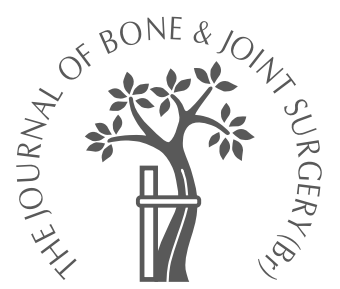

K. Matsuzaki,

N. Nakatani,

M. Harada,

T. Tamaki

From the Wakayama Medical University, Japan
K. Matsuzaki, MD Associate Professor N. Nakatani, MD, Orthopaedic Surgeon T. Tamaki, MD, Professor and Chairman

Department of Orthopaedic Surgery, Wakayama Medical University, 811-1 Kimiidera, Wakayama 641-8510, Japan.

M. Harada, MD,

Orthopaedic Surgeon

Department of Orthopaedic

Surgery, Wakayama Rosai

Hospital, 435 Koya,

Wakayama 640-8435, Japan.

Correspondence should be sent to Dr K. Matsuzaki.

(C)2004 British Editorial Society of Bone and Joint Surgery doi:10.1302/0301-620X.86B2. $13774 \$ 2.00$

$J$ Bone Joint Surg $[\mathrm{Br}]$ 2004;86-B:232-8.

Received 19 August 2002;

Accepted after revision

10 June 2003

\title{
Treatment of supracondylar fracture of the humerus in children by skeletal traction in a brace
}

In 1980, we developed a specially designed brace for treating supracondylar fractures of the humerus in children, along with an easy and safe technique of reduction by skeletal traction. This method, which takes into consideration only the medial tilting and anterior angulation of the distal fragment, achieves complete reduction, ignoring any lateral, posterior and minor rotational displacements of the fragment. Skeletal traction is applied through a screw inserted into the olecranon and the angulation at the fracture site is reduced regardless of the anatomical position without manipulation.

We treated 193 children with displaced supracondylar fractures of the humerus using this method between 1980 and 2001 . Only four children (2\%) developed cubitus varus. The majority obtained an excellent range of movement at the elbow; one had a $25^{\circ}$ limitation of flexion. This technique is an effective and easy method of treating supracondylar fractures of the humerus in children.

Supracondylar fracture of the humerus in children can usually be treated successfully with a good prognosis. Treatment should, if possible, be atraumatic and minimise the stress on the children. The unsightly deformity of cubitus varus which results from medial tilting of the distal fragment should be avoided. ${ }^{1-6}$ It can be difficult, however, to obtain and maintain an anatomical reduction of the shape of the distal humerus. When the fracture is unstable, cubitus varus cannot always be prevented.

Before 1980, our department used several different methods of treatment including manual reduction (cast immobilisation), traction and open reduction, but the incidence of cubitus varus was high, reaching nearly $50 \%$. Traction appeared to be a promising method so in 1980 we devised a skeletal traction brace for children with these fractures (Fig. 1). Reduction by this method relies solely on the application of the brace and traction. No manipulative reduction is undertaken.

\section{Patients and Methods}

Patients. Between 1980 and 2001, we treated 193 children with displaced supracondylar fracture of the humerus using a skeletal traction brace. There were 130 boys and 63 girls. The fracture occurred in the left humerus in 127 and 66 in the right. The mean age was 6.1 years (2 to 14$)$. The highest incidence was at six years. According to the classification of

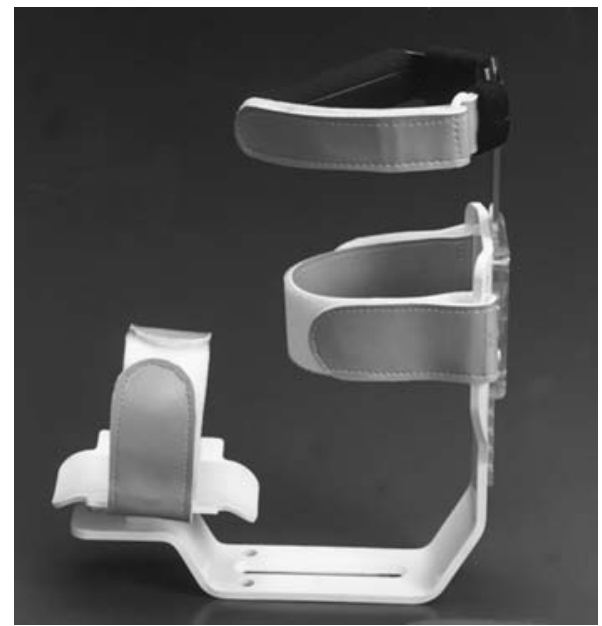

Fig. 1

The brace used to treat supracondylar fractures of the humerus in children.

fractures by Smith, ${ }^{7} 28$ were slightly displaced (type B), 40 were moderately displaced (type C) and 125 were seriously displaced (type D). In addition to this classification, fractures in which the distal fragment had displaced laterally or tilted to a valgus position were classified as valgus type based on the anteroposterior (AP) radiographs. Fractures in which the distal fragment had displaced medially or had tilted into a varus position were classified as varus 


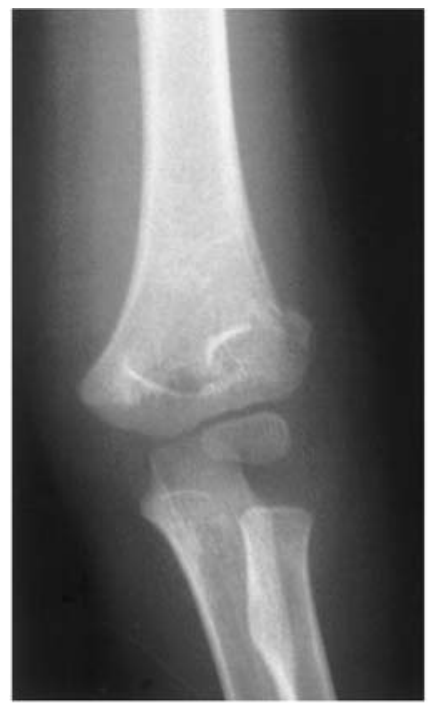

Valgus B

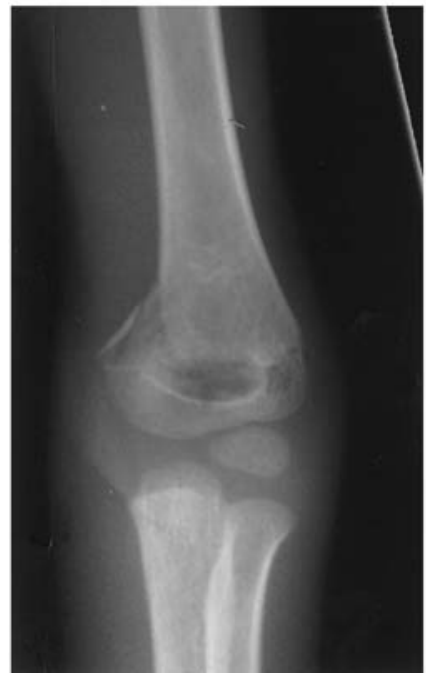

Varus B

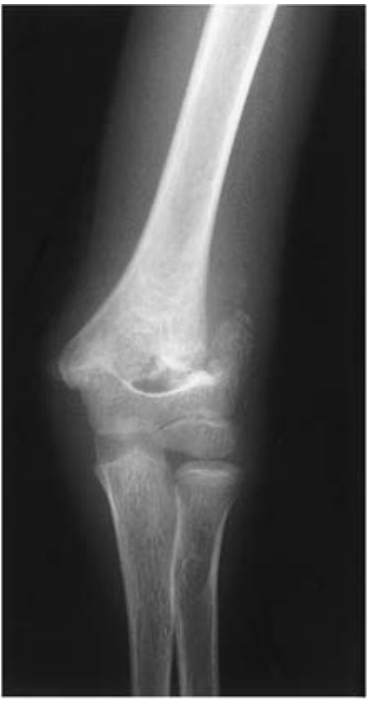

Valgus C

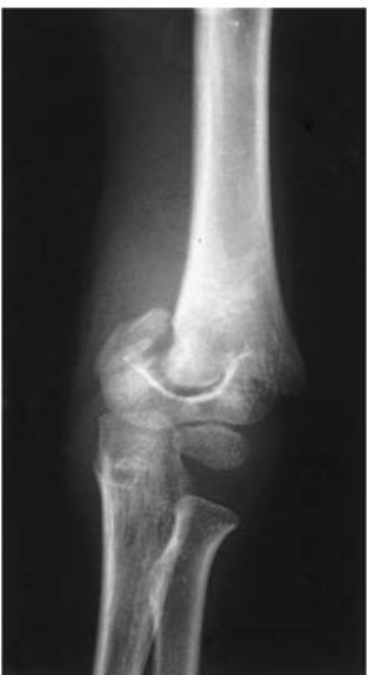

Varus C

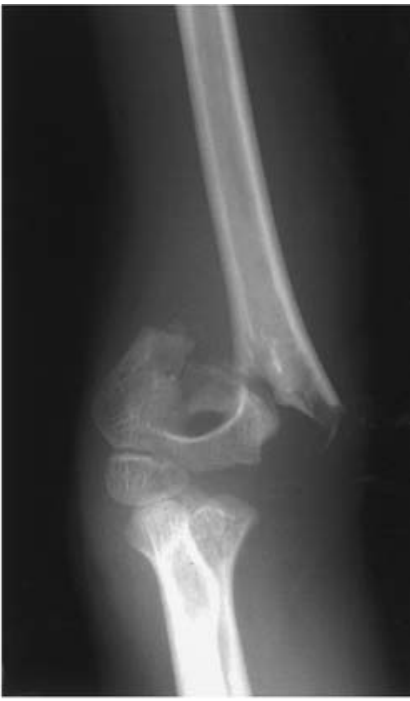

Valgus D

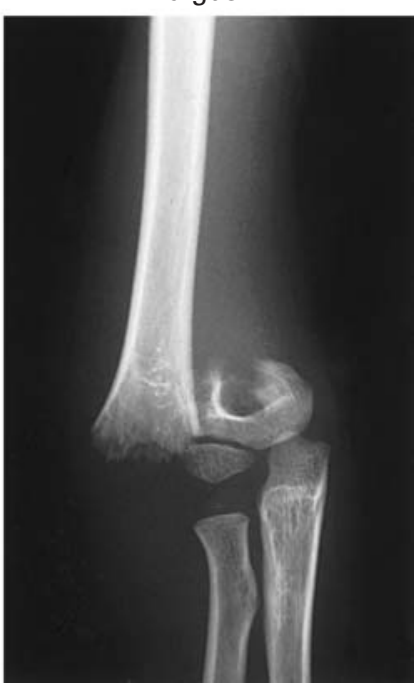

Varus D
Fig. 2

The classification of fractures into valgus and varus according to $\mathrm{Smith}^{7}(\mathrm{~B}$ C and D).

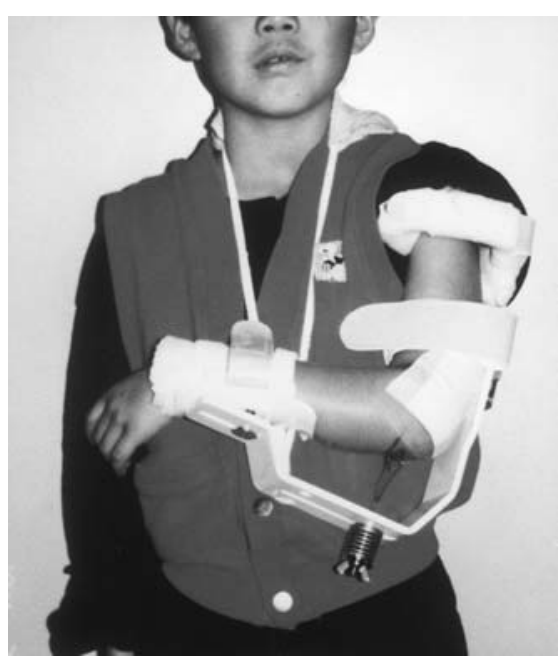

Fig. 3a

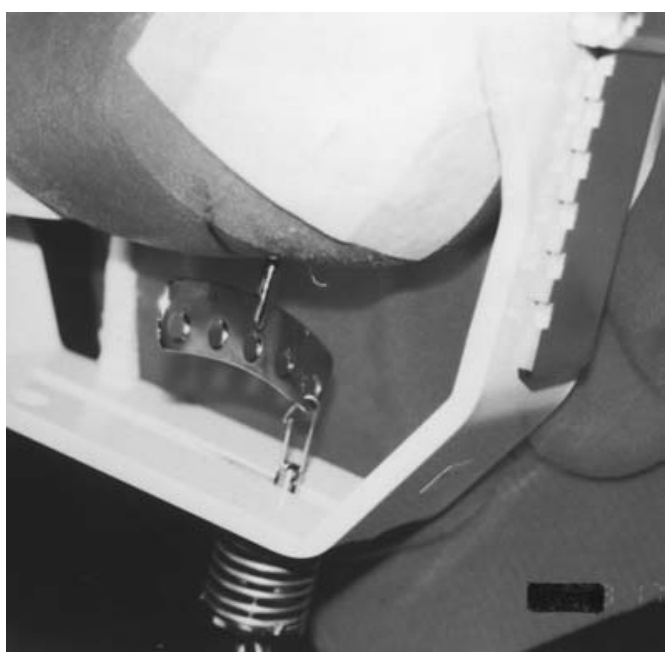

Fig. 3b

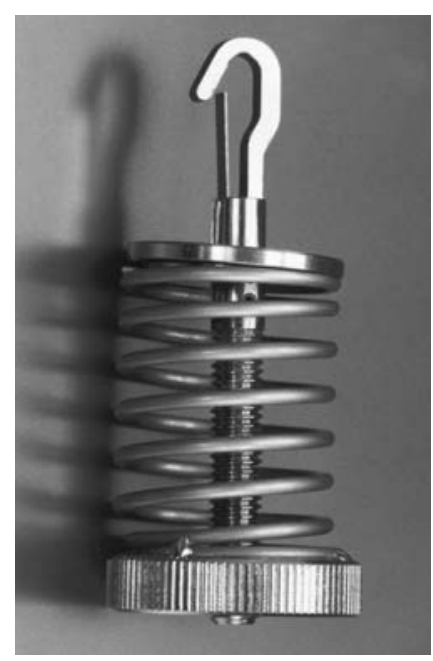

Fig. 3c

Skeletal traction using a) a brace with b) a winged screw inserted into the olecranon and c) a spring to generate a tension of $1.47 \mathrm{~kg}$ for $1 \mathrm{~cm}$ of shortening. 

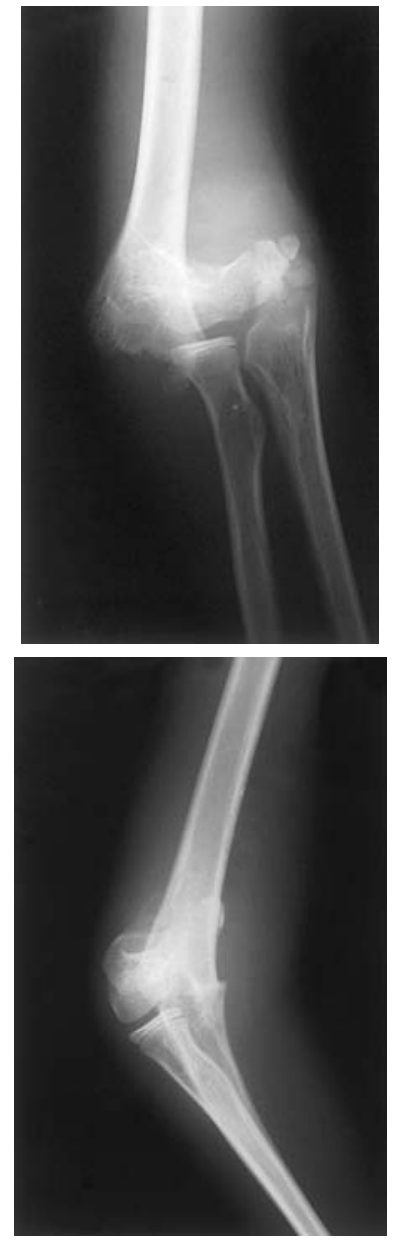

Fig. $4 \mathrm{a}$
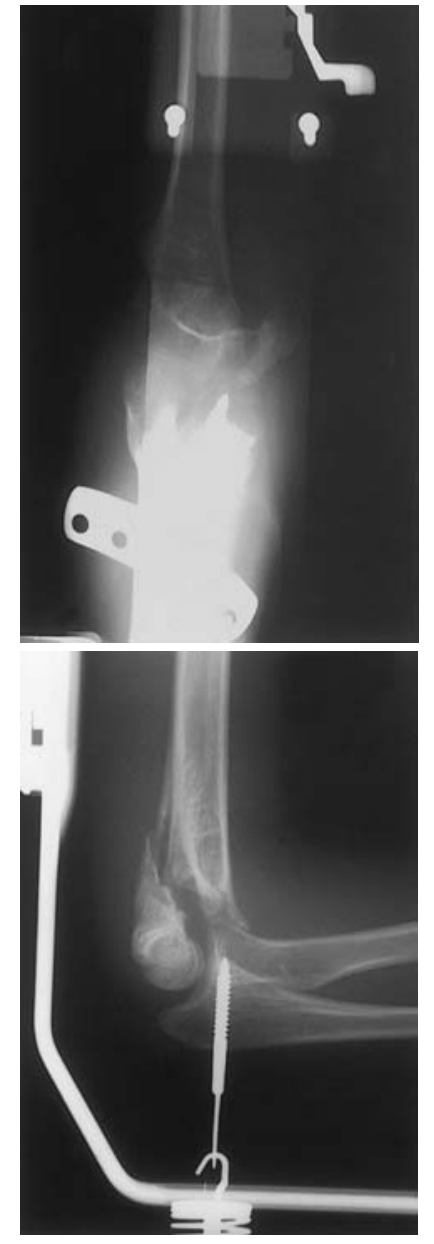

Fig. $4 b$
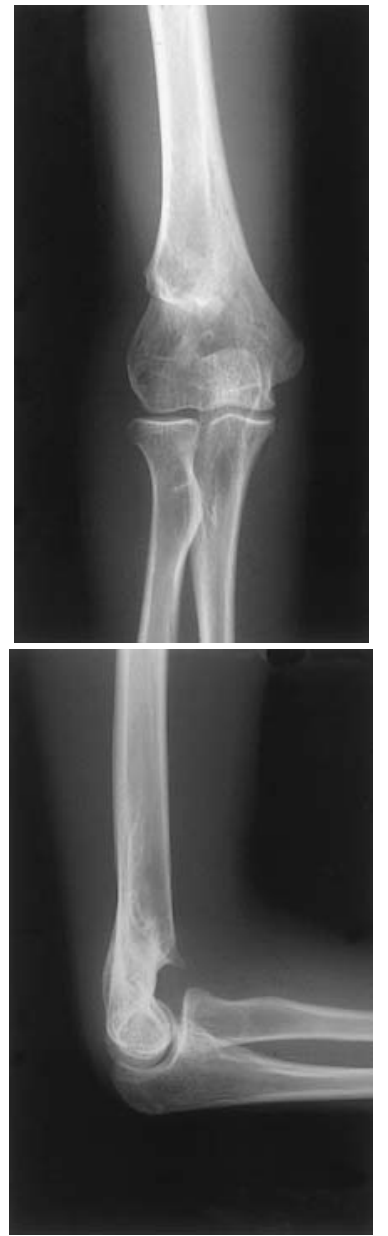

Fig. 4c

AP (top) and lateral views (bottom) of a varus D type fracture in a 12-year-old boy a) at injury, b) 18 days after injury when the apposition is $70 \%$ in AP view and $40 \%$ in lateral view and c) 18 months after injury when the carrying angle loss is only $2^{\circ}$ and the loss of movement, $10^{\circ}$.

type. Of 193 fractures, 103 were classified as valgus type, and 90 as varus (Fig. 2). The mean follow-up period was 3.25 years (0.67 to 14$)$. All children had extension fractures, except one who had a flexion fracture.

Brace. The brace which is made of plastic and aluminium alloy, is strong and radiolucent. Its axillary pad is adjustable by sliding the humeral bar up or down to suit the length of the child's arm. Traction is applied to the fracture site using the axilla for support by inserting a winged screw with a spring into the olecranon. When the brace is in place, held by a bandage, the patient is fully ambulant, and radiographs are easily taken (Fig. 3). The stable position of the fracture in the brace allows accurate assessment of the reduction of the displaced fragments, and facilitates the measurement of Baumann's angle. ${ }^{8,9}$ We normally insert the winged screw under local anaesthetic. Before insertion, we make a small hole in the olecranon manually using a gimlet.
Our method aims to stabilise the fracture with the brace and to apply constant traction (usually with a force of 2.2 $\mathrm{kg}$ for $1.5 \mathrm{~cm}$ of shortening) to the fractured humerus using the screw in the olecranon, so that reduction of the fragments can occur spontaneously. Traction is applied for three to four weeks until stable union is achieved. Throughout treatment, we take care to reduce any medial tilting of the distal fragment in the AP plane. It is also important to obtain good reduction of the anterior angulation (Fig. 4). After removal of the brace the elbow is immobilised in a splint at a right angle for another week to ensure consolidation. Instead of passive exercises, we encourage the children to play with a yo-yo.

\section{Results}

Of the 193 children, 62 (32\%) obtained the same carrying angle and $57(30 \%)$ a greater carrying angle than on the normal side (mean $2.8^{\circ}, 1$ to 9 ). In 74 children (38\%), the 

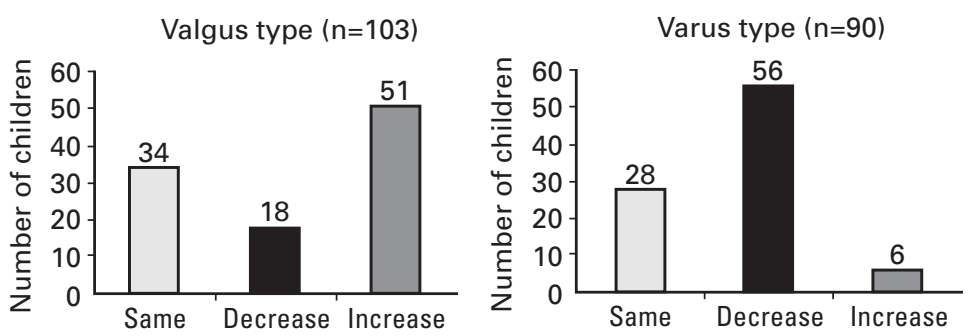

a) Changes in the carrying angles after the valgus and varus type fractures and b) the angles compared with the normal arm. The angle significantly decreased with varus type fractures. The
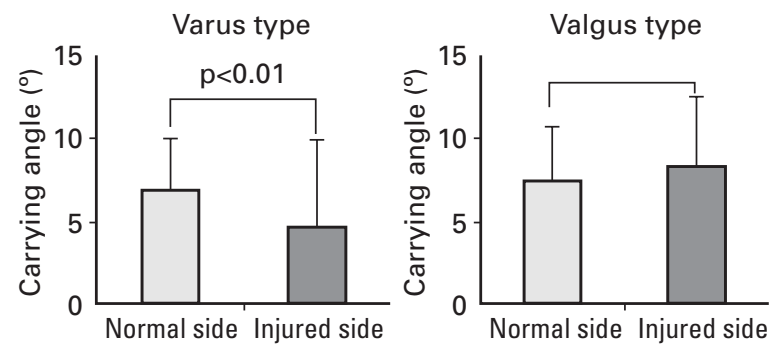

increase after valgus type fractures was not significant.

Fig. $5 b$
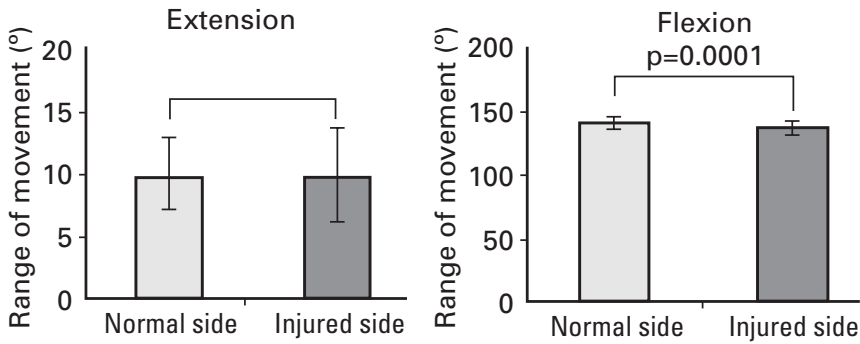

The range of movement of the elbow joint is almost the same as for the normal arm in extension, but significantly decreased in flexion (non paired $t$-test).

Fig. 6

carrying angle was reduced compared with the normal side (mean $-3.6^{\circ},-1$ to -26$)$. In 56 of 90 patients $(62.2 \%$ ) with a varus type fracture the carrying angle was decreased. This was statistically significant $(\mathrm{p}<0.01)$. However, in 51 of 103 patients $(49.5 \%)$ with a valgus type fracture the carrying angle was increased. This was not statistically significant $(\mathrm{p}=0.83)$ (Fig. 5). As shown in Figure 6, there was no final difference in the range of extension of the elbow between the injured and normal sides $(\mathrm{p}=0.9784)$, but the range of flexion on the injured side was significantly decreased $(\mathrm{p}<0.0001)$.

Only four children developed cubitus varus (carrying angle; mean $-15.8^{\circ},-2$ to -26$)$. In two, this was because of errors in the direction of the traction; and in two, insufficient traction was applied. According to the criteria of Flynn, Matthews and Benoit, ${ }^{10}$ of the 136 children with a carrying angle loss, 130 had an excellent, four a good (including two with cubitus varus) and two a poor outcome. Functionally, 178 children had an excellent outcome, three a fair, and one, with a $25^{\circ}$ limitation of flexion, a poor outcome.

Of the 38 children $(20 \%)$ who had associated peripheral nerve injuries, 15 were radial nerve injuries, 14 were median, three were ulnar, five were radial and median, and one was radial and ulnar. Neurological symptoms were noted immediately after injury and none occurred during treatment. They were considered cured when sensory disturbance in the innervated area had disappeared and strength recovered to grade $\mathrm{V}$. All had recovered in six weeks to eight months (mean four months) later. Eight $(4 \%)$ developed contact dermititis due to the rubber on the brace. Eight children (4\%) had ipsilateral forearm fractures which were treated by closed reduction and splintage with a brace. The final range of movement of the forearm and wrist was good. No child developed Volkmann's contracture or ectopic ossification.

Lateral and posterior displacement persisted in some of the 125 patients with complete Type D displacement. It 


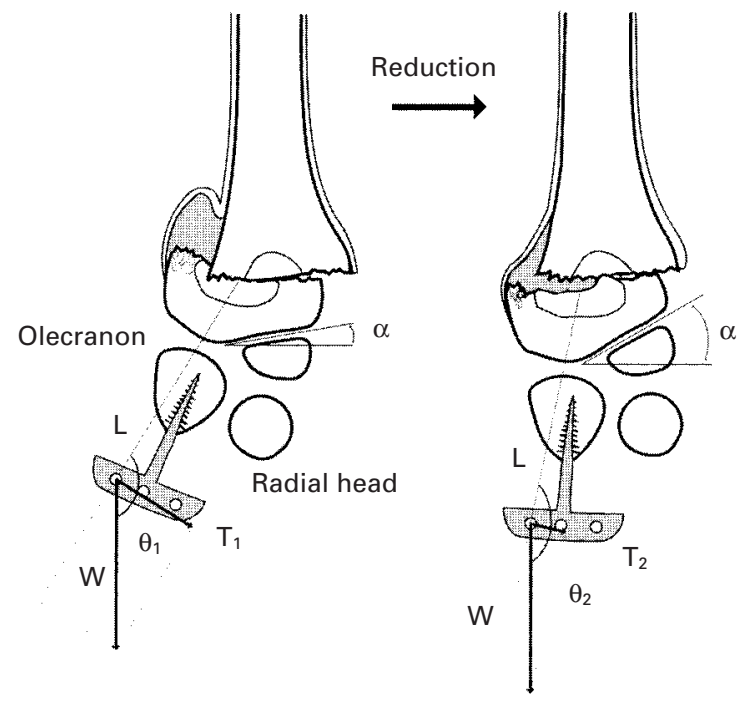

Fig. 7 a

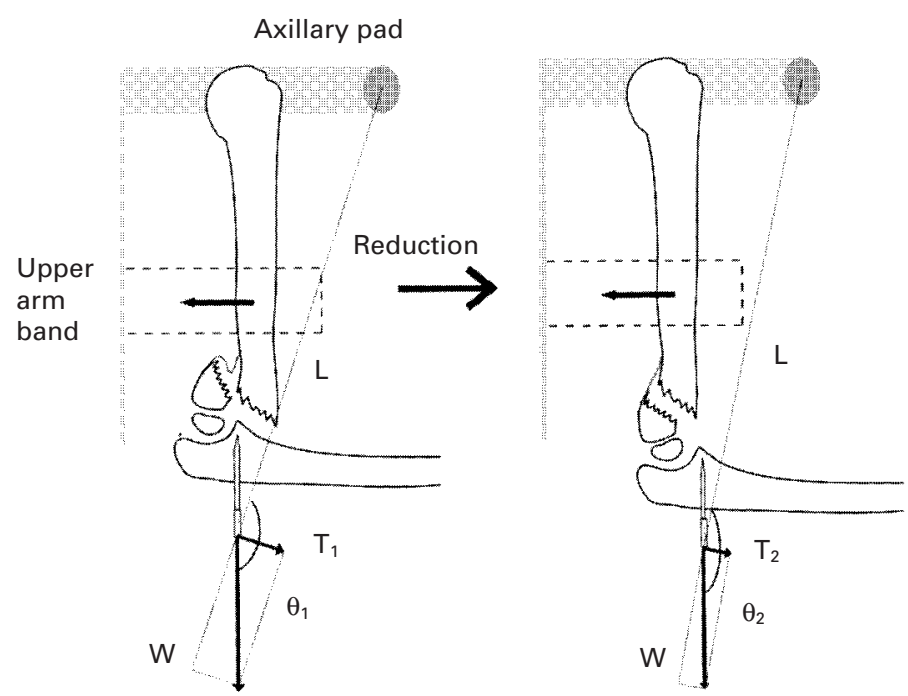

Fig. $7 b$

a) The mechanism for reduction of medial tilting, and b) the mechanism for reduction of anterior angulation (T, Wsin $\theta ; \alpha$, Baumann angle).

was, however, within the range of functional reduction and caused no functional or cosmetic complication.

\section{Discussion}

Supracondylar fractures of the humerus in children have been treated by various methods, including manipulation and immobilisation, ${ }^{11-13}$ continuous traction, ${ }^{1,6,12,14-18}$ percutaneous pinning ${ }^{10,11,17,19,20}$ and open reduction. ${ }^{21-24}$ Clinical results appear generally good using any of these approaches. Percutaneous pinning is the most widely used technique for displaced fractures, although damage to the ulnar nerve is an occasional complication..$^{25,26}$ Cubitus varus remains a complication of certain types of supracondylar fracture. This should be preventable, because it results from medial tilting of the distal fragment and malunion. As the supracondylar portion of the humerus has the deeply indented olecranon fossa on its dorsal side, fractures of this area are difficult to reduce and maintain. ${ }^{5}$ In particular, when the distal fragment is small, medially displaced and comminuted, it is difficult to retain in an anatomical position and this leads to cubitus varus.

Our brace is well suited to such a fracture. It stabilises the fracture, and traction reduces the medial tilting of the distal fragment and prevents re-displacement. The reduction mechanism in the AP plane can be explained (Fig. 7a). When the distal fragment remains tilted medially, the traction (W), exerted by the winged screw through its medial hole, generates a force $(T)$ to reduce the medially tilted fragment. $\mathrm{T}_{1}$ represents the product of traction (W) and $\sin \theta$, while the moment of $T_{1}$ and length $(\mathrm{L})$ yields a reductive force. Initially, $T_{1}$ acts on the fractured bone, even if the medial side of distal fragment is comminuted and has no contact. $\mathrm{T}_{2}$ acts to prevent re-displacement by medial tilt- ing. As the humeral periosteum is presumed to be intact on the medial side, traction (W) can be adjusted to a suitable strength, with no fear of over-correction, so as to bring Baumann's angle $(\alpha)$ in the fractured humerus to that seen in the normal one, and to prevent the development of cubitus varus. In the lateral plane (Fig. 7b), the traction on the elbow flexed at $90^{\circ}$ generates a force $(\mathrm{T})$ which draws the fragment anteriorly, with the axillary pad as a fulcrum. As on the AP plane, $T_{1}$ is the product of traction (W) and $\sin \theta$ and correct anterior angulation. $\mathrm{T}_{2}$ acts to maintain the reduction. As the force is borne by the belt on the upper arm, counter-traction develops in the belt, which corrects for any anterior angulation of the distal fragment as similar to that for the AP plane. If some posterior displacement and anterior angulation remain, we often use a rubber band with a hook to connect to the winged screw to pull the fragment forward. The periosteum, although extensively detached from the posterior aspect of the humerus, remains intact and can thus safely be subjected to strong traction without fear of over-correcting the fracture.

Our method concentrates on the reduction of medial tilting and anterior angulation; lateral, posterior and rotational displacement is ignored. Also manipulative reduction is never used. Therefore, mild lateral, posterior and rotational displacement may persist. The reduction is not thus truly anatomical, but remodelling at the fracture site satisfactorily corrects the lateral and posterior displacements, as confirmed by radiography. ${ }^{12,18,27-29}$

Lateral and posterior displacement persisted in some patients with complete type D displacement. It, however, caused no functional or cosmetic complications. Extensive remodelling can take place as shown in Figures 8 and 9. In our experience, satisfactory remodelling can take place in 


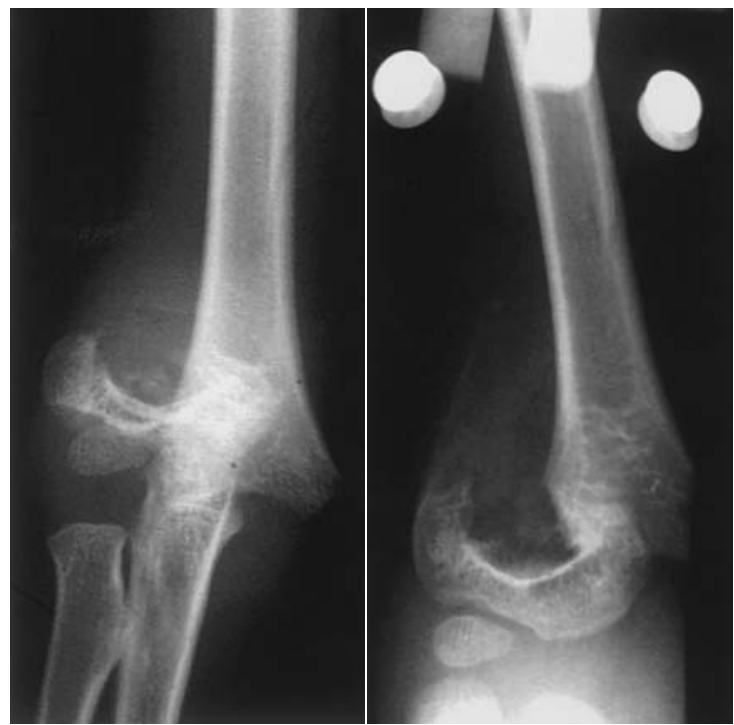

Fig. 8a

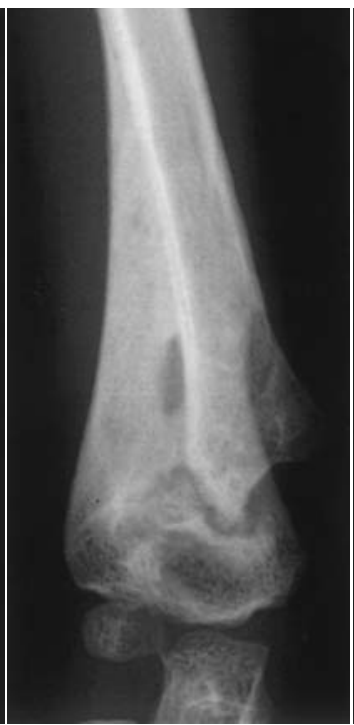

Fig. 8c

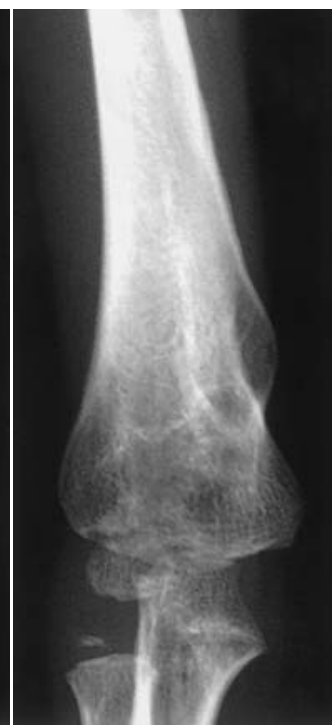

Fig. 8d

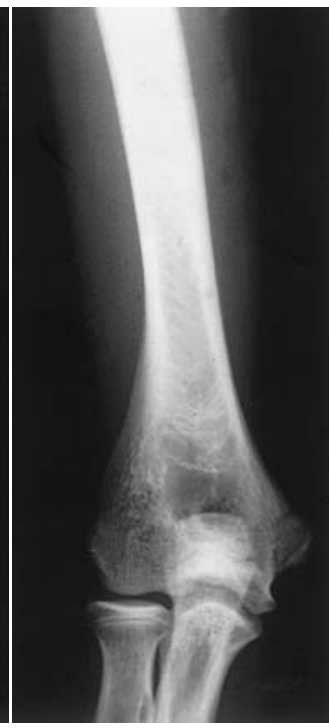

Fig. 8e

AP radiographs showing remodelling in a five-year-old boy. He was exceptional in that the apposition was $38 \%$. a) At injury, and b) three weeks, c) three months, d) 15 months and e) seven years after injury.

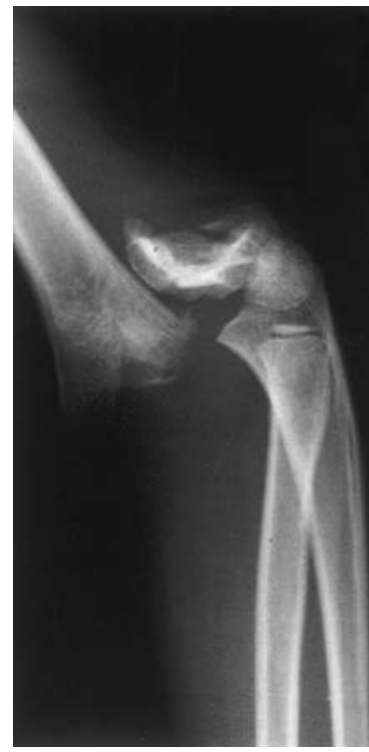

Fig. 9a

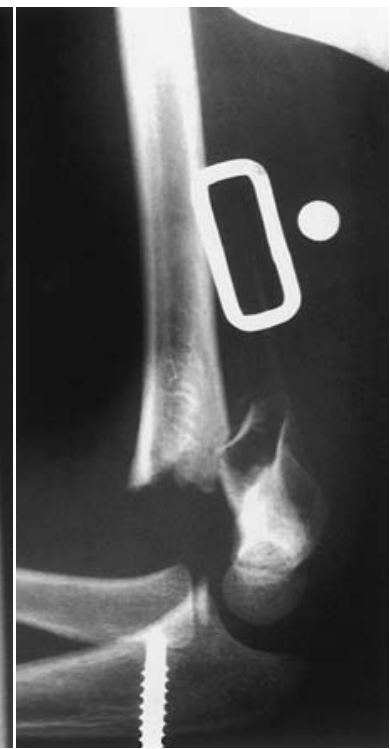

Fig. 9b

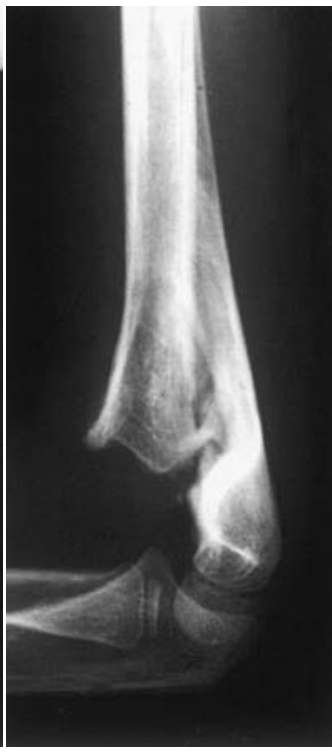

Fig. 9c

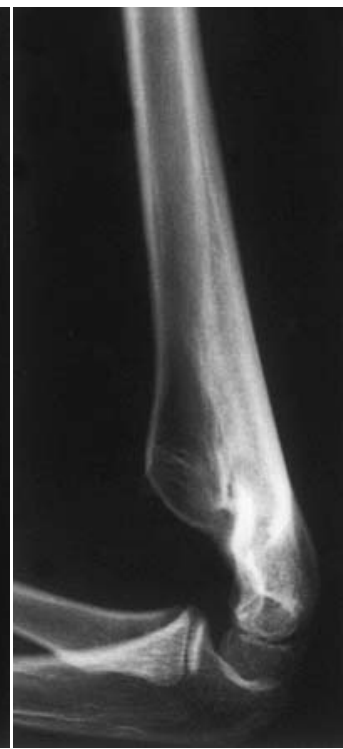

Fig. 9d

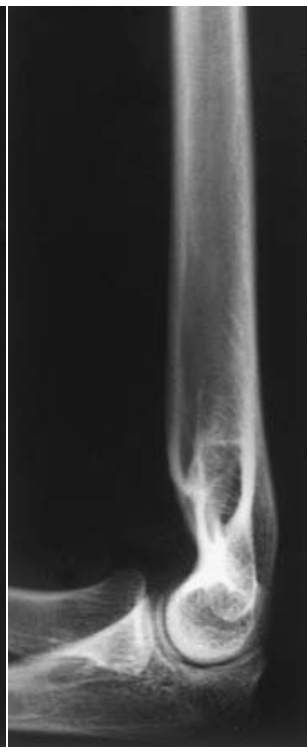

Fig. 9e

Lateral radiographs showing remodelling in a six-year-old girl (apposition 0\%). a) At injury, and b) ten days, c) eight weeks, d) nine months and e) six years after injury.

children up to the age of 12 years in whom the epiphyseal line remains open.

The decreased range of flexion of the injured elbow was due to insufficient reduction of the tilting angle in extension fractures. The significant decrease in the carrying angle in many patients with the varus type and the non-significant increase in patients with the valgus type fracture was prob- ably because maintaining the reduced position is difficult as the supracondylar column is narrow. In particular, because the medial column has less bony mass and is smaller than the lateral column, the medial column may be more comminuted, and this is a cause of a decreased carrying angle. ${ }^{18} \mathrm{It}$ is necessary to pay attention to this, because cubitus varus may arise as a complication in children in whom the carry- 
ing angle is small, as in the varus type. These residual displacements, however, were slight, and acceptable functionally and cosmetically in all children, except four with cubitus varus and one with limited elbow flexion.

Brücke ${ }^{30}$ has previously reported a method for treating this fracture with a brace. His method is based on skin traction through the forearm using a spring. Høyer ${ }^{31}$ also devised a brace for skeletal traction by means of a rubber band, with the shoulder held in abduction. These methods appear to be essentially different from ours in that they include manipulative reduction.

Our method reduced medial tilting and anterior angulation in children with a supracondylar fracture of the humerus. We applied our brace to 193 children with displaced fractures and obtained satisfactory results. Cubitus varus was noted only in four children $(2 \%)$, and the final range of movement of the elbow joint was satisfactory.

No benefits in any form have been received or will be received from a commercial party related directly or indirectly to the subject of this article.

\section{References}

1. D'Ambrosia RD. Supracondylar fractures of humerus: prevention of cubitus varus. $J$ Bone Joint Surg [Am] 1972;54-A:60-6.

2. Labelle H, Bunnell WP, Duhaime M, Poitras B. Cubitus varus deformity following supracondylar fractures of the humerus in children. J Pediatr Orthop 1982;2:539-46.

3. Langenskiöld A, Kivilaakso R. Varus and valgus deformity of the elbow following supracondylar fracture of the humerus. Acta Orthop Scand 1967;38:313-20.

4. Mitchell WJ, Adams JP. Supracondylar fractures of the humerus in children: a ten year review. JAMA 1961;175:573-77.

5. Rang M. Children's fractures. Second ed. Philadelphia: J B Lippincott, 1983:152-69.

6. Smith L. Deformity following supracondylar fractures of the humerus. J Bone Joint Surg [Am] 1960;42-A:235-52.

7. Smith FM. Supracondylar fractures in children: surgery of the elbow. Philadelphia: Saunders, 1972:69-102.

8. Baumann E. Beitrage zur Zenntnis der Frakturen am Ellbogengelenk unter besonderer Berucksichtigung der Spatfolgen: Allegemeines und Fraktura suprakondylica. Beitr Klin Chir 1929;146:1-50.

9. Camp J, Ishizue K, Gomez M, Gelberman R, Akeson W. Alteration of Baumann's angle by humeral position: implications for treatment of supracondylar humerus fractures. J Pediatr Orthop 1993;13:521-5.

10. Flynn JBC, Matthews JG, Benoit RL. Blind pinning of displaced supracondylar fractures of the humerus in children: sixteen years' experience with long-term followup. J Bone Joint Surg [Am] 1974;56-A:263-72.
11. Kennedy JG, El Abed K, Soffe K, et al. Evaluation of the role of pin fixation versus collar and cuff immobilisation in supracondylar fractures of the humerus in children. Injury 2000;31:163-7.

12. Piggot J, Graham HK, McCoy GF. Supracondylar fractures of the humerus in children: treatment by straight lateral traction. J Bone Joint Surg [Br] 1986;68-B:577-83.

13. Williamson DM, Cole WG. Treatment of selected extension supracondylar fractures of the humerus by manipulation and strapping in flexion. Injury 1993;24:249-52.

14. Badhe BNO, Howard PW. Olecranon screw traction for displaced supracondylar fractures of the humerus in children. Injury 1998;29:457-60.

15. Dunlop J. Transcondylar fractures of the humerus in childhood. J Bone Joint Surg 1939;21:59-73

16. Palmer EE, Niemann KM, Vesely D, Armstrong JH. Supracondylar fracture of the humerus in children. J Bone Joint Surg [Am] 1978;60-A: 653-6.

17. Pirone AM, Graham HK, Krajbich JL. Management of displaced extension-type supracondylar fractures of the humerus in children. J Bone Joint Surg [Am] 1988; 70-A:641-50.

18. Wilkins KE, Rockwood CA, Beaty JH. Fractures and dislocations of the elbow region. In: Fractures in children. Fourth ed. Philadelphia: J B Lippincott, 1996:669-752.

19. Mazda K, Boggione C, Fitoussi F, Pennecot GF. Systematic pinning of displaced extension-type supracondylar fractures of the humerus in children: a prospective study of 116 consecutive patients. J Bone Joint Surg [Br] 2001;83-B:888-93.

20. Mehserle WL, Meehan PL. Treatment of the displaced supracondylar fracture of the humerus (type III) with closed reduction and percutaneous cross-pin fixation. J Pediatr Orthop 1991;11:705-11.

21. McKee MD, Kim J, Kebaish K, et al. Functional outcome after open supracondylar fractures of the humerus: the effect of the surgical approach. J Bone Joint Surg [Br] 2000;82-B:646-51.

22. Ramsay RJ, Griz J. Immediate open reduction and internal fixation of severely displaced supracondylar fractures of the humerus in children. Clin Orthop 1973;90:131-2.

23. Skaggs DL, Hale JM, Bassett J, et al. Operative treatment of supracondylar fractures of the humerus in children: the consequences of pin placement. $J$ Bone Joint Surg [Am] 2001;83-A:735-40.

24. Weiland AJ, Meyer S, Tolo VT, Berg HL, Mueller J. Surgical treatment of displaced supracondylar fractures of the humerus in children: analysis of fifty-two cases followed for five to fifteen years. J Bone Joint Surg [Am] 1978;60-A:657-61.

25. Rasool MN. Ulnar nerve injury after K-wire fixation of supracondylar humerus fractures in children. J Pediatr Orthop 1998;18:686-90.

26. Taniguchi Y, Matsuzaki K, Tamaki T. latrogenic ulnar nerve injury after percutaneous cross-pinning of supracondylar fracture in a child. J Shoulder Elbow Surg 2000;9: 160-62.

27. Attenborough CG. Remodelling of the humerus after supracondylar fractures in childhood. J Bone Joint Surg [Br] 1953;35-B:386-95.

28. Worlock PH, Colton C. Severely displaced supracondylar fractures of the humerus in children: a simple method of treatment. J Pediatr Orthop 1987;7:49-53.

29. Vahvanen V, Aalto K. Supracondylar fracture of the humerus in children: a long-term follow-up study of 107 cases. Acta Orthop Scand 1978;49:225-33.

30. Brücke H. Die Behandlung der suprakondylären Humerus-fraktur, unter besonderer Berücksichitgung der Abduktionsschiene nach Gold. Dtsh Chir 1932;237:429-40.

31. Høyer A. Treatment of supracondylar fracture of the humerus by skeletal traction in an abduction splint. J Bone Joint Surg [Am] 1952;34-A:623-37. 